\title{
OBSTACLES IN PCI PERMITTING
}

\author{
Bernd Rajal*
}

By adopting the new TEN-E Regulation 347/2013/EU a European step towards a facilitated and accelerated licensing of PCIs was made by installing certain procedural rules. Still, there are several factual and legal challenges to face, which may inhibit or delay the licensing procedures of PCIs.

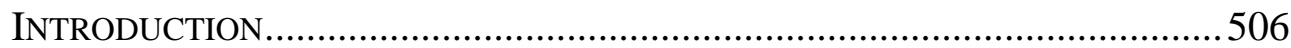

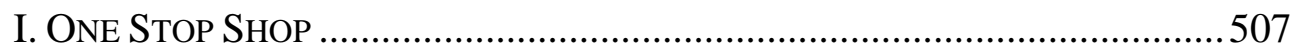

A. Sufficient Personnel Resources of the Coordinating Authority 508

B. Experienced Personnel .............................................................. 508

C. Considering Preliminary and Ancillary Procedures.................509

D. Enforceability of Time Limits .................................................509

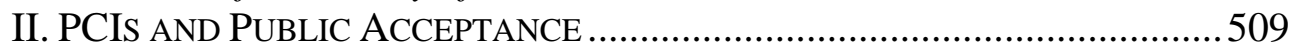

III. PCIS AND EU ENVIRONMENTAL LEGISLATION .....................................510

A. Environmental Impact Assessment (EIA) ................................510

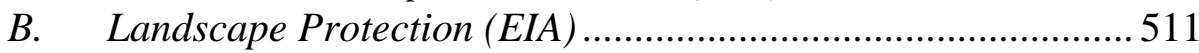

C. Species Protection Regime ….................................................511

IV. Potential FOR IMPROVEMENT OF PCI LEGISLATION AND POLICY .......512

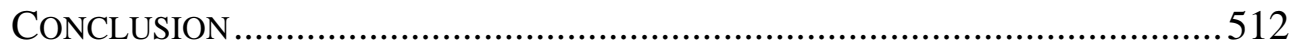

\section{INTRODUCTION}

EU primary law (Art 154 ECT/Art170 TFEU) says that the Union must contribute to the establishment and development of trans-European energy networks (TEN-E).The reason for this is quite simple: isolated national energy networks constitute a significant obstacle to the establishment of an internal market in Europe. Therefore, the expansion of trans-European energy networks is of utmost importance for the functioning of the European Union.

Based on that various Parliament and Council Decisions laying down guidelines for the development of trans-European networks were adopted (TEN-E Guidelines/Decision No 391/1996/EC and 1364/2006/EC). The aim of the guidelines was to list and rank network projects, inter alia Project of Common Interest (PCIs), eligible for Community assistance. Besides those guidelines, various other regulations and programs for financial grants were

\footnotetext{
* Mag., Rechtsanwalt/Attorney at Law Partner, Wien. Research fields: Energy Law (Gas, Oil, Renewables), Infrastructure Projects, Environmental Law.
} 
implemented, such as the TEN Financial Regulation 2007 and the European Energy Programme for Recovery (EEPR) in 2009.

However, all these regulations turned out to be more or less insufficient. Many PCIs were significantly delayed and therefore not implemented within the expected timeframe. The reasons for those delays were multi-fold and it is therefore impossible to address all of them within this presentation (for details pls see European Commission Report dated 13 October 2014). The major obstacles are related to:

1. Legal and regulatory framework

- Long duration of the permitting procedures (mainly caused by the fact that a PCI requires manifold authorization and permitting procedures at different administrative levels)

- Lack of harmonization of the permitting procedures along the route, especially in case of cross-border projects

- Lack of public acceptance causing delays in permitting

2. Financial and technical constraints

- Lack of appropriate incentives for investors and network operators

It is against this background in particular that the TEN-E Regulation was fundamentally revised and replaced by the new TEN-E Regulation 347/2013/EU which was adopted on April 17, 2013. That new regulation follows a revolutionary new approach. On the one hand it aims at identifying PCIs in 12 energy infrastructure priority corridors covering all types of infrastructure such as power lines, pipelines, water storages for pumped storage HPPs, gas storages, equipment etc. And on the other hand, and this can be considered really revolutionary, it sets forth procedural rules for PCI permitting on national and cross-border level. Those core rules provide for:

1. Mandatory one-stop-shop permitting procedure

2. Setting a mandatory time limit for permitting procedures

3. Priority status of PCIs on national level

4. Increased transparency/participation of the public

\section{ONE STOP SHOP}

In the chapter at hand, the author is going to question whether the procedural requirements for the organization of national permitting procedures introduced by the new TEN-E regulation are actually suitable to accelerate the permitting procedures for PCIs.

As mentioned before, the permitting procedures for PCIs take much too long or sometimes even end negatively, meaning that permits are denied. 
The EC report of October 2014 has come to the conclusion that this problem is mainly due to the large number of different permits that are required for a project which have to be granted by various authorities on different administrative levels. The TEN-E Regulation therefore provides for a mandatory designation of a one stop shop for PCIs, the publication of manuals of procedures for PCIs and streamlining of EIA procedures.

From practical experience the author is of the opinion that the one stop shop may facilitate procedures and can thus contribute to increasing efficiency. But it will be necessary to create a proper framework for the one stop regime. Otherwise, the one stop shop will be more bane than boon. Unfortunately, the TEN-E Regulation does not address these requirements. Which requirements are meant?

\section{A. Sufficient Personnel Resources of the Coordinating Authority}

The practice of permitting procedures has repeatedly shown that authorities do not have sufficient personnel resources to evaluate large infrastructure projects, neither as regards the number of lawyers to conduct procedures or the number of experts. Policy-makers obviously lack awareness that submitting a large infrastructure project involves an extreme workload. A submission does not consist of a single technical report but, regularly, of dozens of file folders with several thousand pages of paper. For instance, the submission for an Austrian PCI included 50 file folders, 11,500 pages, 550 plans and 700 individual documents.

\section{B. Experienced Personnel}

Large energy infrastructure projects are of enormous legal and technical complexity. As a rule, the one stop shop even increases such complexity because all permit granting requirements and technical aspects must be evaluated, or at least coordinated, by one authority. This applies to all procedures shown in the TEN-E regulation. For an efficient conduct of procedures you need many years of experience and extensive professional expertise to concentrate on the relevant procedural aspects of a complex project. Unfortunately, the situation is quite different in practice. Frequently lawyers and, above all, experts are overburdened and get bogged down in insignificant details. Professional project opponents are very quick to realize that and know how to take advantage of that situation for their own benefits. 


\section{Considering Preliminary and Ancillary Procedures}

Every large energy infrastructure project, whether a power transmission line, gas pipeline or storage facility, usually entails extensive preliminary investigations, which may require approval themselves. These so-called preliminary or ancillary procedures are not subject to the one stop shop principle or the time limits applicable to procedures. But they may also cause significant delays in the implementation of a PCI. Against this backdrop, it might be reasonable to consider applying the regulations of PCI procedures also to preliminary and ancillary procedures.

\section{Enforceability of Time Limits}

Although the proposed limitation of procedures in terms of time is absolutely necessary, it will unfold its force only when compliance therewith is ensured on a national level. However, the first transposing acts in the Member States have shown that such compliance has generally not been ensured. In practice, no effective sanctions are imposed if time limits are exceeded. It must also be borne in mind that the requirements of EU law concerning the duration of permitting procedures are not applicable to appellate or opposition proceedings; and experience has shown that it is precisely these procedures that take very long.

\section{PCIs ANd Public AcCEPTANCE}

Another problem constitutes the lack of acceptance by the public or by land owners and neighbors directly affected by a project. The Commission report of October 2014 highlighted this as a particularly critical problem because the implementation of projects may be significantly delayed when permits are challenged before an authority or a court. The Commission believes that the TEN-E regulation takes account of this problem insofar as the public affected must now be informed of a project early on in the process. However, based on the author's experience in connection with permit granting procedures the author is not convinced that providing the public with early and comprehensive information will automatically increase acceptance.

We must face up to the fact that apart from opponents open to constructive dialog, large infrastructure projects almost always attract numerous fundamentalist project opponents. They have the same procedural rights as all other parties and use early project information to stir up public opinion against the project early on. 
Further on, it has to be noted that the lack of public acceptance is regularly not linked to a specific PCI but caused by the lack of general understanding of the functioning of the European energy market. It is very difficult to convince people of the necessity of PCI implementation when they are not aware of the strategic importance of network and infrastructure expansion in Europe. The author therefore believes that EU and MS policy must work on increasing public acceptance by providing more comprehensive and easy to understand information on the importance of PCI implementation. And this should not be done on the occasion of a particular PCI permitting procedure.

To avoid any misunderstanding: It is not to the author to judge whether the reinforcement of public participation in PCI permitting procedures is justified or not. But out of the author's practice it can be told that the reinforcement of rights of the interested public to participate in a permitting procedure will definitely not accelerate procedures.

\section{PCIS AND EU ENVIRONMENTAL LEGISLATION}

The Commission report of October 2014 states that the different regulatory frameworks, including those referring to the protection of the environment, cause delays in the implementation of PCIs. This is something the author can only confirm. But there is another problem that does not occur on Member State level but on Union level and should also be resolved there, namely an increasingly strict interpretation of EU environmental law.

\section{A. Environmental Impact Assessment (EIA)}

One problem Austria and many other EU Member States are encountering in the context of permit granting processes is the requirement under the EIA Directive that project-related environmental impact must generally be counterbalanced by compensatory measures. Such compensatory measures must regularly be related to protected resources and bear a relation to the location in terms of space and substance. In practice, often no compensatory measures are available, which means that some environmental impact simply cannot be counterbalanced. Often compensatory measures cannot be implemented for lack of necessary land and areas. The lack of compensatory measures regularly results into a refusal of the permit, although the EIA Directive does not provide for a full counterbalancing of negative impacts. Against this backdrop, I believe it would be reasonable to create so-called "measure pools" from which project promoters can choose an environmentally sensible and realizable 
compensatory measure that fits their project. The establishment of such measure pools could also contribute to increasing acceptance by environmental NGOs and by the public in general.

\section{B. Landscape Protection (EIA)}

The Austrian Federal Administration Court denied the EIA permit for a PCI cross-border power line between Austria and Italy because the project would result into negative impact on the largely unaffected landscape. Although the respective region has not been subject to any special nature or environmental protection rules (such as NATURA 2000, national park, landscape protection area), the Austrian Court argued that the maintaining of unaffected landscape elements is overweighing the public and common interest of Trans-European network expansion. With this kind of way of interpreting environmental protection rules it will be very difficult to realize PCIs within a proper timeframe, since every power line PCI is linked to negative impacts on the landscape, unless the project is constructed in residential areas where the public acceptance for such kind of projects approaches the level of "zero".

\section{Species Protection Regime}

Another obstacle to infrastructure projects, especially to power line projects is the species protection scheme under the Fauna-Flora-Habitat and Birds Directives. If construction measures or the creation of high-tension power lines are considered a "deliberate" disturbance of birds and thus a violation of the no-disturbance obligation in terms of the Birds Directive, it will be difficult for project promoters of power line projects to obtain a permit within a reasonable period of time. Unfortunately, Art 7 Para 8 of the Birds Directive, which qualifies the PCIs as projects of public interest, does not go far enough in this respect because (1) it only addresses the derogation in respect of NATURA 2000 sites without including the derogation applicable to species protection contained in the Birds Directive, and (2) the biggest obstacle to obtaining a permit is regularly not posed by a balancing of interests, but by other derogation criteria.

There is no doubt that environmental protection and preservation of nature are important and should not be watered down in large energy infrastructure projects. But I believe we need a better sense of proportion when it comes to interpreting the environmental regulations of EU law, which were certainly not adopted to prevent or significantly hamper the implementation of PCIs. 


\section{Potential For IMPROVEMENT OF PCI LEgISLATION AND Policy}

Binding personnel requirements for the infrastructure authority and/or permit granting authority

1. Extension of the one stop shop principle to preliminary and ancillary procedures

2. Maximum time limits for procedures must be enforceable by a project promoter and applicable to subsequent appellate procedures

3. Potential public involvement should not be boundless.

4. Creation of measure pools that may make it easier to obtain a permit for a project and increase acceptance of PCIs.

5. EU environmental protection regulations, such as the Water Framework Regulation and the NATURA 2000 Directive, should be flexible in respect of PCIs to find an adequate solution for inextricable contradictions between project goals and environmental goals.

\section{CONCLUSION}

Even though efforts were made on European level to facilitate the licensing of PCIs, project applicants face a multitude of legal and factual burdens which may slow down or even impede the proceedings. One of the most delaying factors is the large volume of project documentation which is produced during licensing procedures: The handling of this documentation does not only require sufficient personnel with extensive experience but also consumes a lot of time.

Also the consultation of the affected public, especially if fundamentalist project opponents make use of their participatory rights, is a relevant factor which prevents quick decisions.

Finally, rigid and inflexible application of environmental legislation is an aspect which may not only slow down but may ultimately impede the realization of PCIs.

It will be the task of policy makers to outbalance the identified obstacles in PCI licensing procedures by enacting respective countermeasures. 